\title{
Atomization of UMo Particles under Nitrogen Atmosphere
}

\author{
Luis Olivares ${ }^{1}$, Jaime Lisboa ${ }^{1}$, Jorge Marin'1, Mario Barrera ${ }^{1}$, Alberto Navarrete ${ }^{2}$ \\ ${ }^{1}$ Nuclear Materials Department, Chilean Commission for Nuclear Energy (CCHEN), Santiago, Chile \\ ${ }^{2}$ Physic Department, Universidad de Santiago de Chile (USACH), Santiago, Chile \\ Email: "Iolivare@cchen.cl, "jlisboa@cchen.cl
}

Received 1 January 2016; accepted 4 January 2016; published 7 January 2016

Copyright (C) 2016 by authors and Scientific Research Publishing Inc.

This work is licensed under the Creative Commons Attribution International License (CC BY).

http://creativecommons.org/licenses/by/4.0/

c) (i) Open Access

\section{Abstract}

Generally, the atomization of UMo particles is done under vacuum or argon atmosphere, and the surface modification of these UMo particles is, usually, carried on through a further process. The techniques for surface modification of atomized UMo particles, aimed to control the Fuel/Matrix interaction, involve, in some cases, complex methodologies and often with minor effect due to the limited solubility of third elements in solid UMo alloy. The atomization and surface conditioning, applied in separate stages, may affect the efficiency of powder production process. Then, the main goal of this study is to explore the surface modification of UMo particles in liquid state or during the solidification that follows the centrifugal atomization process. Through the change of atomization atmosphere, could be possible to promote liquid/gas reactions, with a higher solubility of the modifier element in micro drops of UMo alloy, before they become solid particles. This paper presents comparative results of centrifugal atomization of UMo particles, carried out under inert argon and reactive nitrogen atmospheres. Dissolved nitrogen contents, measured by SEM-EDS analyses, reached up to $7.57 \mathrm{wt} \%$ at the center of under nitrogen atomized particles, very higher than $0.84 \mathrm{wt} \%$ of nitrogen measured at the center of UMo particle atomized under argon. The presence of uranium nitride was partially verified by conventional XRD analysis. Nevertheless, Out-of-Pile interaction test result, reveals decreasing of aluminium contents into UMo particles atomized under nitrogen atmosphere; Just $3.77 \mathrm{wt} \%$ of $\mathrm{Al}$ was the maximum content detected in the center of these particles, very lower than $29.11 \mathrm{wt} \%$ of Al measured inside UMo particles atomized under argon. Finally, it is possible to conclude that the atomization under reactive atmosphere may modify the surface composition and the behavior of UMo fuel particles dispersed in aluminium, for dispersion type nuclear fuel application.

\section{Keywords}

Atomization, UMo Particles, Dispersion, Nuclear Fuel

\footnotetext{
${ }^{*}$ Corresponding authors.
} 


\section{Introduction}

The qualification of high density nuclear fuel based on UMo alloy requires, necessarily, solve the fuel/matrix interaction issues. Several articles, which cover in detail that topic, have already been written and published by nuclear fuel experts and also by researchers of the CCHEN's Fuel Development Group [1]. An effective way to control the interdiffusion between aluminum matrix and UMo fuel, is related to the surface coating of the UMo particles, so as to form diffusion barriers, which can help to avoid or delay the interaction layer occurrence, and the consequent formation of compounds with poor in-reactor performances, as $\mathrm{U}_{6} \mathrm{Mo}_{4} \mathrm{Al}_{43}$ and/or $\mathrm{UAl}_{4}[2]$.

According to the available literature, several methodologies have been developed for surface coating of UMo particles, some of them based on solid-solid reactions, as the pack cementation technique to form silicon-rich surface layers [3], others based on solid-gas reactions, such as thermal treatments under nitrogen atmosphere to form uranium nitride layers [4], and solid-plasma reactions, such as PVD or CVD applied to the formation of Zr or ZrN layer [5]. In general, all these methodologies are carried out with UMo fuel particles in solid state, which limits the solubility of the element added to modify the surface.

Specifically for Uranium-Nitrogen binary system [2], whose phase diagram is shown in Figure 1, the solubility of nitrogen at the melting point of uranium is about $10 \mathrm{ppm}$ [6] [7], while at $2800^{\circ} \mathrm{C}$, the uranium nitride decomposes and forms a liquid phase, containing $4.6 \mathrm{wt} \%$ of U. According to the analysis of Bugl J. et al. [6], the uranium would form a eutectic with the UN, so that the solubility could be even lower at the annealing temperatures applied for particles surface coating.

Due to the solubility limitations, besides the previous observation that the effectiveness of the UN coating appeared to be small [3], the idea is to attempt the dissolution of nitrogen into UMo alloy in liquid state, which would allow reaching higher solubility of nitrogen and increase the probability to form stable compounds.

Being the centrifugal atomization, the most generalized method and, apparently, the most proper for UMo alloy particles production, the goal of this study is to propose the modification of the surface of UMo particles, during the atomization process, in which the alloy is, by short time, in liquid state. Depending on the feasibility of implementation, this could be a suitable surface modification process for UMo particles, considering industrialization and economic issues.

This paper reports results of reactive atomization conducted under nitrogen atmosphere. This gas is easily available, nevertheless, other reactive gas, such as methane or methane-nitrogen mixture, also could be applied as a way to promote the formation of surface layers, rich in uranium carbide or uranium carbo-nitrides, compounds initially considered as fuel for fast breeder reactor [8].

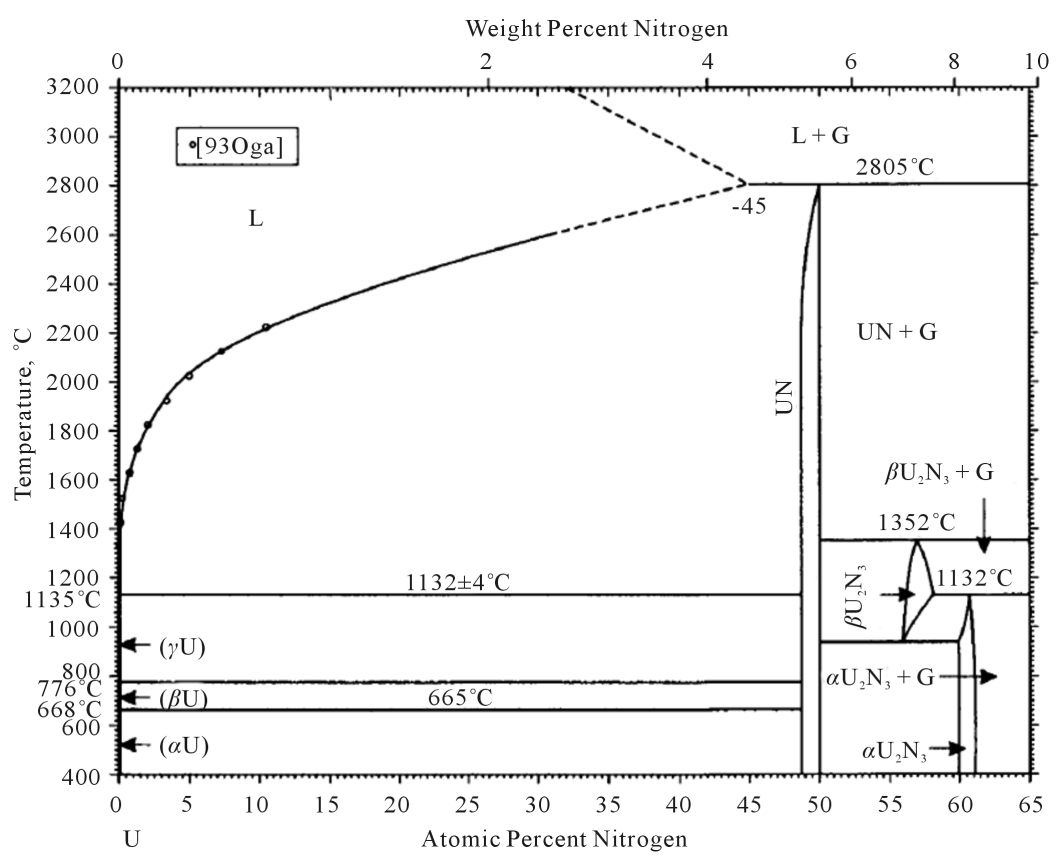

Figure 1. Binary Phase Diagram for uranium-nitrogen [7]. 


\section{Experimental Set-Up}

\subsection{Atomization Process}

The atomization of cylindrical pins to produce UMo alloy particles was carried out in a laboratory scale centrifugal atomizer, described in a previous paper [9]. Since one of the main characteristics of the Rotating Electrode Process-REP is his versatility for the construction of laboratory designs and designs for facilities on a large scale of major importance [10]-[12]. In case of this work, the atomizer chamber is located inside a glove box, capable to operate under controlled atmosphere or rough vacuum. The atomized UMo particles were characterized by SEM-EDS and XRD. The atomization process was carried out with the following parameters (Table 1).

\subsection{Interaction Test}

Out-of-Pile interaction test were conducted using mini compacts prepared with UMo particles dispersed in $\mathrm{Al}-4 \mathrm{wt} \% \mathrm{Si}$ blend. The total mass of compacts was $0.4 \mathrm{~g}$. To avoid excessive oxidation of samples, the compacts were annealed, at $500^{\circ} \mathrm{C}$ by 4 hours, in vacuum and inside a copper envelope. After that, the compacts were mounted in epoxy resin, sectioned and prepared to cross section examination through SEM-EDS microanalyses.

Standard Tyler meshes were used to evaluate the granulometry of UMo particles.

\subsection{Miniplates Manufacturing}

Using standard methodologies of hot and cold rolling, a set of 6 miniplates was manufactured, with uranium densities of 6, 7 and $8 \mathrm{gU} / \mathrm{cm}^{3}$. For comparative analysis, a second set of miniplates, with the same densities, was manufactured using UMo particles atomized under argon. QA\&QC of miniplates includes; Industrial X-Ray, Ultrasonic Scanning Test, optical densitometry, cladding thickness measurement by Eddy current and cross section examination by SEM and optical microscopy.

\section{Results and Discussion}

The granulometry of UMo particles atomized under nitrogen and argon atmospheres, selected for miniplates manufacturing, are summarized on Table 2 and Table 3, respectively. The percent of fine particles in the nitrogen atomized alloy was $6.68 \%$, much less than fine particles produced by argon atomization (31.56 wt\%). Due to the excess of fine particles, 11.28 grams of material $<45 \mu \mathrm{m}$ were removed, prior to manufacture the miniplates. Considering the particle size range chosen for experimental test (45 and $150 \mu \mathrm{m}$ ), the atomization under argon atmosphere results more efficient for fine particles production. In terms of material recovery, the centrifugal atomization process applied at CCHEN can be considered as high efficiency process, near to 99\%, comparable with the results of standard atomization described in [13].

The differences in particle size distribution between the two systems could be related to the presence of dissolved nitrogen in the liquid UMo alloy, which increases the melting point and decreases the density of the alloy. According to centrifugal atomization models, these variations increase the particle diameter [10].

The shape of the UMo particles atomized in nitrogen and argon, inspected by Scanning Electron Microscope and EDS analysis, are shown in the micrographs of Figure 2 and Figure 3, respectively. Some irregular forms are observed, however the spherical morphology is predominant, and this is due to the superficial tension, according to the author K. H. Kim [14], the spherical particles exhibits surface layers, apparently brittle. The high

Table 1. Operational parameters for centrifugal atomization process.

\begin{tabular}{cc}
\hline Parameter & Value \\
Gas Flow (Argon or Nitrogen) & 12 liters/minute (welding torch) \\
Alloy composition & U + 7 wt $\%$ Mo (natural uranium) \\
Pins diameter & $8-10 \mathrm{~mm}$ \\
Mass of pins & $38-54 \mathrm{~g}$ \\
Angular speed & $40,000 \mathrm{rpm}$ \\
Welding Machine Current Intensity & $60 \mathrm{amps}$ \\
\hline
\end{tabular}


Table 2. Granulometry of UMo particles atomized in nitrogen.

\begin{tabular}{|c|c|c|c|}
\hline \multicolumn{4}{|c|}{ Lot Identification: U7Mo-REP-NAT-L12 } \\
\hline \multicolumn{2}{|c|}{ Tyler Sieve } & \multicolumn{2}{|c|}{ Material below ${ }^{*}$} \\
\hline$\#$ & Mesh $[\mu \mathrm{m}]$ & [g] & [\%] \\
\hline 100 & 150 & 21.84 & 100.00 \\
\hline 170 & 90 & 9.81 & 47.36 \\
\hline 230 & 63 & 4.66 & 23.72 \\
\hline 325 & 45 & 5.18 & 12.48 \\
\hline Total & ---- & 41.49 & ----- \\
\hline
\end{tabular}

*Excluding the material $>150 \mu \mathrm{m}$; Total atomized material: $36.11 \mathrm{~g}+41.49 \mathrm{~g}=77.6 \mathrm{~g}$; Mass of particles $>150 \mu \mathrm{m}$ : 36,11g; corresponding to $46.5 \mathrm{wt} \%$ of total; Mass of particles $<150 \mu \mathrm{m}: 41,49 \mathrm{~g}$ corresponding to $53.5 \mathrm{wt} \%$ of total; Mass of particles $<45 \mu \mathrm{m}$ : $5.18 \mathrm{~g}$ corresponding to $6.68 \mathrm{wt} \%$ of total.

Table 3. Granulometry of UMo particles atomized in Argon.

\begin{tabular}{|c|c|c|c|}
\hline \multicolumn{4}{|c|}{ Lot Identification: U7Mo-REP-NAT-L11 } \\
\hline \multicolumn{2}{|c|}{ Tyler Sieve } & \multicolumn{2}{|c|}{ Material below ${ }^{*}$} \\
\hline \# & Mesh $[\mu \mathrm{m}]$ & [g] & [\%] \\
\hline 100 & 150 & 22.25 & 100.00 \\
\hline 170 & 90 & 6.37 & 46.13 \\
\hline 230 & 63 & 4.99 & 30.70 \\
\hline 325 & 45 & 7.69 & 18.62 \\
\hline Total & ----- & 41.30 & ----- \\
\hline
\end{tabular}

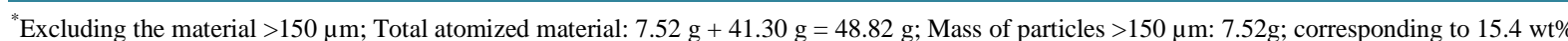
of total; Mass of particles $<150 \mu \mathrm{m}$ : 52.58g corresponding to $84.6 \mathrm{wt} \%$ of total; Mass of particles $<45 \mu \mathrm{m}: 7.69 \mathrm{~g}+11.28 \mathrm{~g}$ (removed of the Lot) $=$ $18.97 \mathrm{~g}$, corresponding to $38.86 \mathrm{wt} \%$ of total.
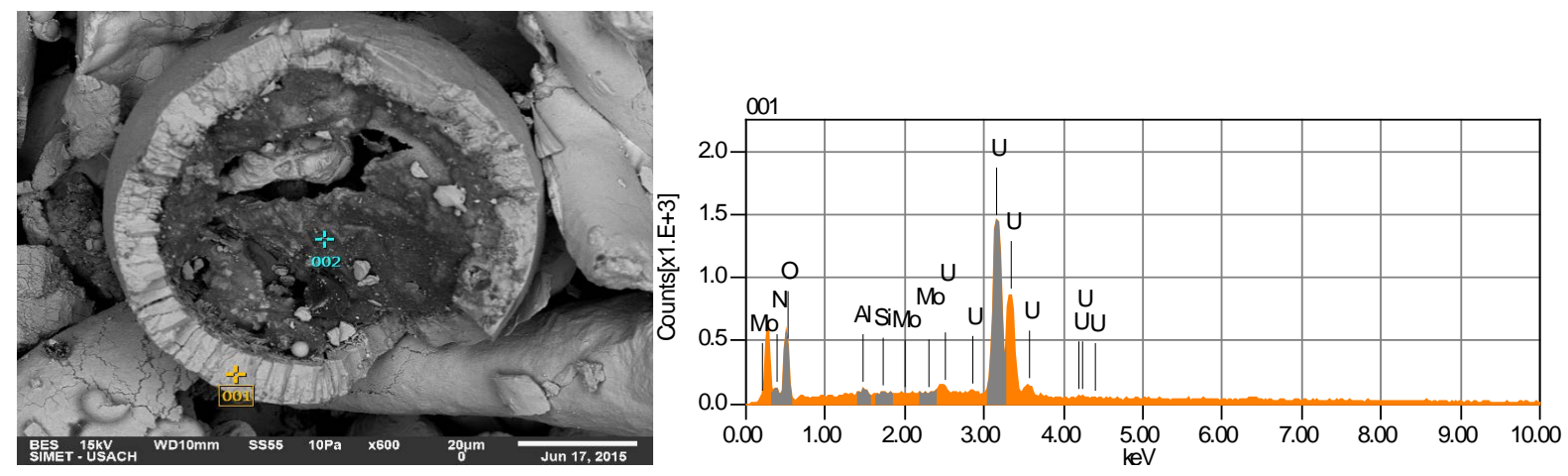

Figure 2. SEM micrographs and EDS analyses of UMo particles atomized in nitrogen.
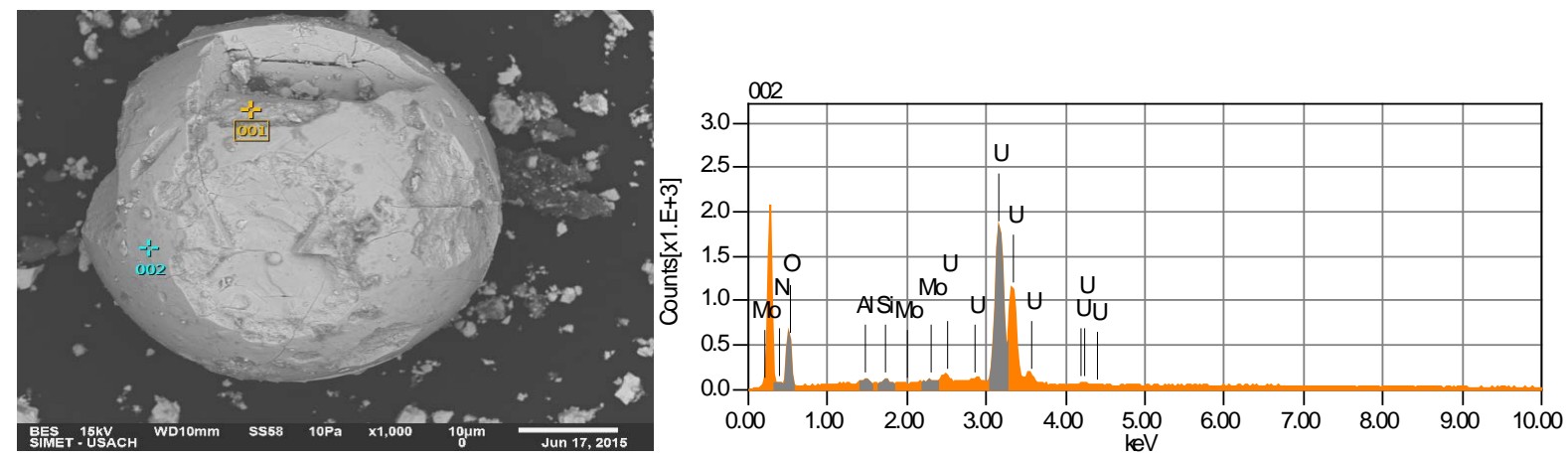

Figure 3. SEM micrographs and EDS analyses of UMo particles atomized in argon. 
oxygen content detected by punctual microanalysis on the surface of the UMo particles, verifies the formation of uranium oxide layers, with thicknesses in the order of $5 \mu \mathrm{m}$, as is possible to observe in the Figure 2 (left).

According to the EDS results summarized in Table 4, the nitrogen content in the surface is slightly higher for the UMo particle atomized under nitrogen. On the other hand, the nitrogen contents measured by LECO analyzer, were 0.70 and $0.33 \mathrm{wt} \%$, for nitrogen and argon atomization, respectively.

The U-7\%Mo particles atomized under nitrogen and argon atmospheres was inspected analytically with X-Ray diffraction in a diffractometer (Shimadzu XRD 6000) with $\mathrm{CuK} \alpha$ radiations and divergence and reception slots of $1.0^{\circ}$ and $0.3^{\circ} \mathrm{mm}$, respectively. Diffraction patterns of particles atomized in nitrogen and argon atmospheres were done, for theta angles, between $10^{\circ}$ and $120^{\circ}$ degrees, with steps of $0.02^{\circ}$ and $1^{\circ}$ second. The X-Ray diffraction patterns of atomized U-7\%Mo alloy powders are shown in Figure 4.

In the UMo atomized particles with sizes below $150 \mu \mathrm{m}, \mathrm{U} \gamma$ (bcc) solid solution metastable was detected; this phase can be retained in a metastable state at room temperature by Mo addition and fast solidification [14]. The $\mathrm{UO}_{2}$ compound was detected in both types of UMo particles; these oxides correspond to superficial oxidation and have a depth of $5 \mu \mathrm{m}$ approximately, as is possible to observe in the Figure 2. The powders atomized in nitrogen atmosphere present, additionally, the compound uranium nitride UN in the surface, which evidence that during the process of atomization, superficial nitriding of the UMo particles occurs. The compound UN was not detected in the sample atomized in argon, according to XRD patterns included in Figure 4.

The samples for the interaction test were prepared blending aluminium powder with UMo particles, and then pressing the mix into a die of $8 \mathrm{~mm}$ diameter, using a load of $260 \mathrm{MPa}$. The samples were placed into copper envelopes for interaction annealing test, carried out under vacuum for 4 hours at $500^{\circ} \mathrm{C}$. After that, the samples were mounted in epoxy resin and prepared through metallographic techniques, grinded and polished after each thermal treatment. Optical and Scanning Electron Microscopy—SEM equipped with Energy Dispersed Scanning-EDS microanalyses were used for characterization of fuel particles and interaction layer.

The result of interaction test, included in Figure 5 and Figure 6, reveals the formation of fuel/matrix Interaction Layer (IL). Nevertheless, the content of $\mathrm{Al}$ in the center of fuel particle atomized in nitrogen is practically the half than the measured content into the UMo particle atomized in argon (see Table 5). No significant differences were observed in the content of others element present at the system.

EDS analyses results evidence the effect of nitrogen as diffusion barrier to avoid Al migration from matrix to inner of UMo particle during U-Al interaction annealing test. The aluminium content into UMo particles atomized under nitrogen is very lower than the content detected into UMo particles atomized in argon atmosphere,

Table 4. Microanalysis results at the surface of UMo particles, corresponding to Figure 2 and Figure 3.

\begin{tabular}{ccccc}
\hline Atomization Atmosphere & \multicolumn{2}{c}{ Nitrogen (Figure 2) } & \multicolumn{2}{c|}{ Argon (Figure 3) } \\
\hline Point of analysis & \multicolumn{2}{c}{ Surface (001) } & \multicolumn{2}{c|}{ Surface (002) } \\
\hline Element & Mass (\%) & Atom (\%) & Mass (\%) & Atom (\%) \\
\hline N & 1.4 & 12.66 & 0.96 & 9.04 \\
O & 4.6 & 34.49 & 4.45 & 36.76 \\
Mo & 0.02 & 0.02 & 0.20 & 0.28 \\
U & 93.79 & 49.97 & 94.02 & 52.16 \\
\hline
\end{tabular}
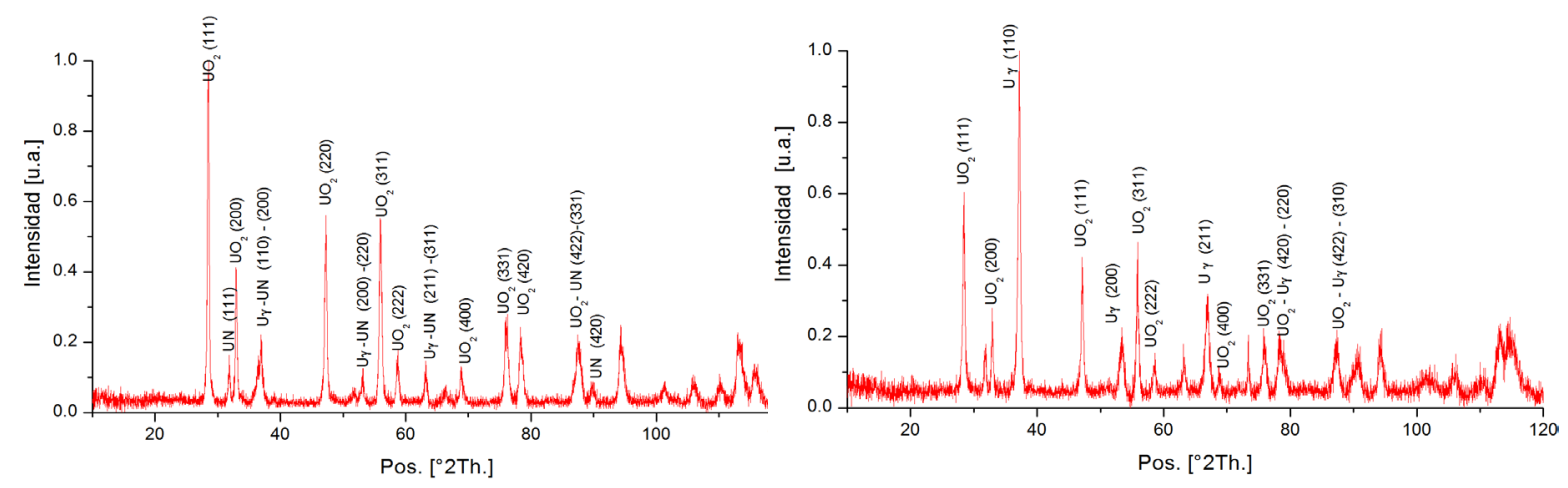

Figure 4. X-Ray diffraction patterns of UMo particles atomized in nitrogen (left) and atomized in argon (right). 

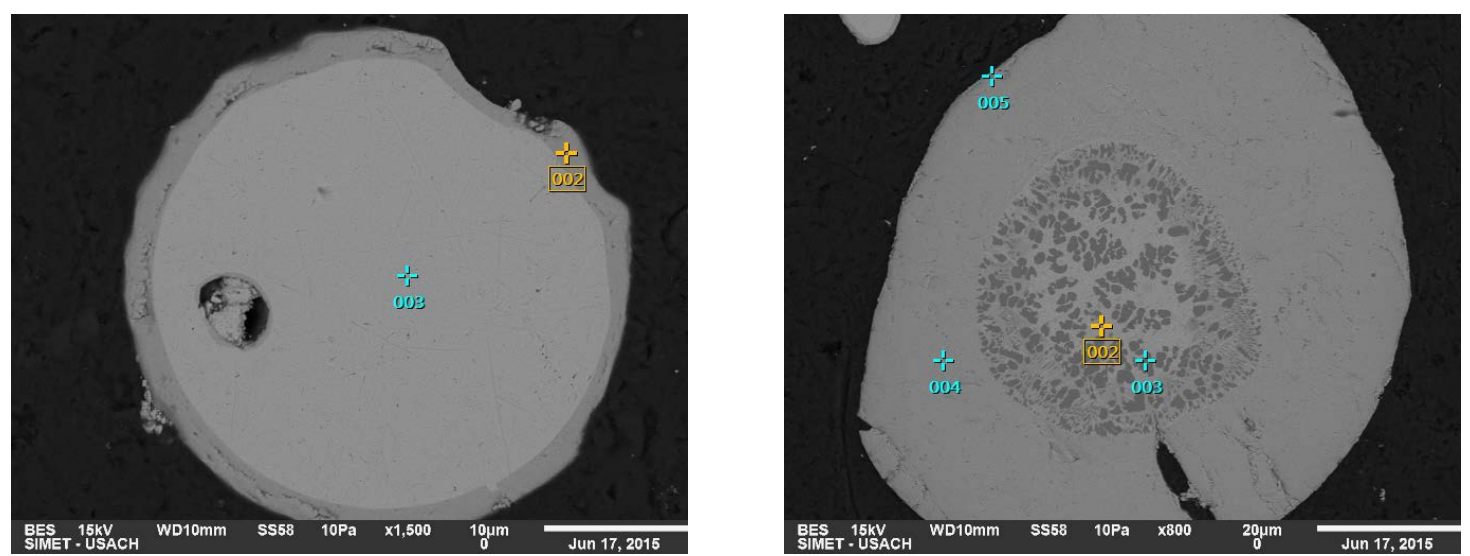

Figure 5. UMo particles atomized under nitrogen atmosphere, after interaction annealing $\left(500^{\circ} \mathrm{C} / 4\right.$ hours).
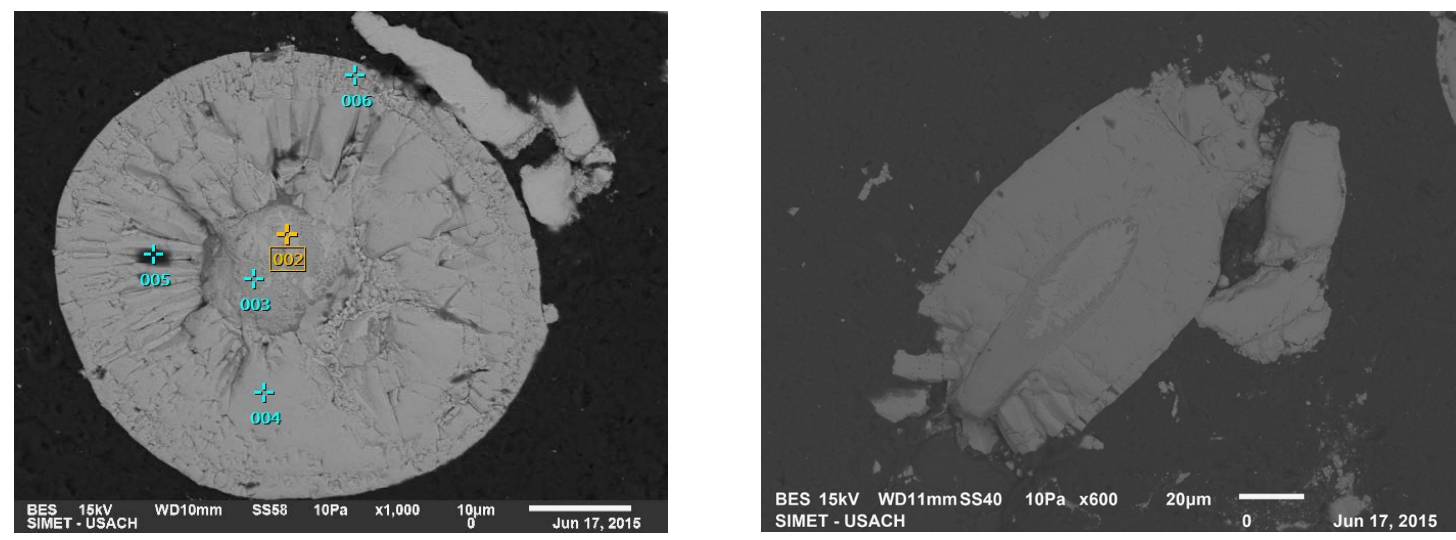

Figure 6. UMo particles atomized under argon atmosphere, after interaction annealing $\left(500^{\circ} \mathrm{C} / 4\right.$ hours $)$.

Table 5. Microanalysis results corresponding to the samples showed in Figure 5 and Figure 6.

\begin{tabular}{|cccccccccc}
\hline $\begin{array}{c}\text { Atomization Atmosphere } \\
\text { Point of analysis }\end{array}$ & \multicolumn{4}{c}{ Nitrogen (Figure 5 right) } \\
\hline Element (Mass \%) & Center (2) & Center (3) & Inter zone (4) & Surface (5) & Center (3) & Center (2) & Inter layer (4) & Surface (6) \\
\hline N & 1.58 & 1.24 & 3.17 & 0.95 & 1.32 & 2.23 & 2.53 & 0.93 \\
O & 1.68 & 0.93 & 3.49 & 3.64 & 3.90 & 3.17 & 5.85 & 5.27 \\
Al & 2.48 & 1.87 & 1.77 & 90.47 & 3.65 & 2.20 & 1.91 & 89.86 \\
Si & 0.06 & 0.15 & 0.10 & 0.41 & 0.12 & 0.04 & 0.06 & 0.88 \\
U & 32.34 & 82.71 & 91.37 & 4.43 & 90.40 & 92.17 & 89.50 & 2.91 \\
Mo & 61.58 & 13.10 & 0.11 & 0.10 & 0.61 & 0.19 & 0.14 & 0.15 \\
\hline
\end{tabular}

minimizing the probability to promote the formation of U-Al compounds due to interaction, results completely agreed with previous studies [15] [16].

The miniplates were manufactured including blending of $\mathrm{UMo}+\mathrm{Al}-4 \% \mathrm{Si}$ powders, compacting, assembling (compact, covers and frame), welding, hot rolling, blister test, cold rolling and QA inspections. In Table 1 is included a summary of fabrication parameters for the complete batch of 6 miniplates.

Table 6 summarizes the SEM-EDS microanalyses results of UMo particles atomized under nitrogen and argon after interaction annealing, whose SEM micrographs were included in Figure 7. Regarding to nitrogen contents, it reached up to $7.57 \mathrm{wt} \%$ at the center of particle atomized under nitrogen, very higher than $0.84 \mathrm{wt} \%$ of nitrogen measured at the center of UMo particle atomized under argon. The results also reveals decreasing of aluminium contents into UMo particles atomized under nitrogen atmosphere; Just $3.77 \mathrm{wt} \%$ of $\mathrm{Al}$ was the maximum content detected in the center of the particle, very lower than $29.11 \mathrm{wt} \%$ of Al measured inside UMo particle atomized under argon. 
According to data included in Table 7, the total reduction applied to UMo miniplates was in the order of 74\%, lower than $\mathrm{U}_{3} \mathrm{Si}_{2}$ dispersion fuel plates made of, in which the total reduction is approximately $85 \%$. Compared with miniplates made of hydrided powder, the reduction rate and total reduction are slightly higher than those used for atomized powder miniplates [11].
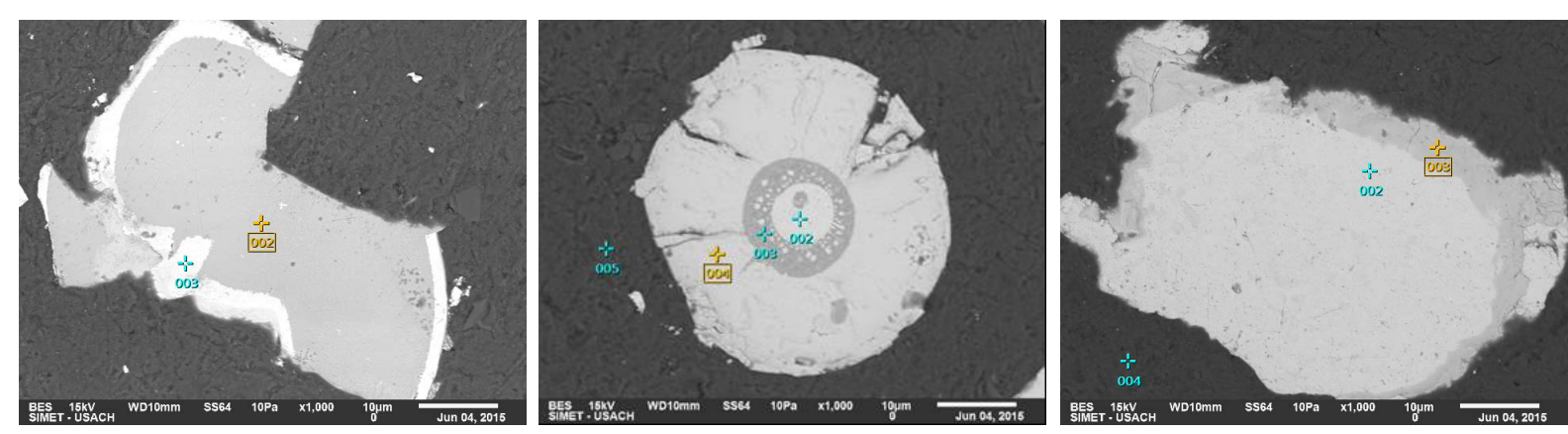

Figure 7. SEM micrographs of Mo particles atomized under nitrogen atmosphere (left and center). UMo Particle atomized in argon (right). All samples after interaction annealing ( $500^{\circ} \mathrm{C} / 4$ hours).

Table 6. Microanalysis results corresponding to the samples of Figure 7.

\begin{tabular}{|c|c|c|c|c|c|c|c|c|}
\hline Atomization Atmosphere & \multicolumn{2}{|c|}{ Nitrogen (Figure 7 left) } & \multicolumn{3}{|c|}{ Nitrogen (Figure 7 center) } & \multicolumn{3}{|c|}{ Argon (Figure 7 right) } \\
\hline \multicolumn{9}{|l|}{ Point of analysis } \\
\hline Element (Mass \%) & Inter layer (3) & Center (2) & Inter layer (4) & Inter zone (3) & Center (2) & Inter layer (3) & Matrix (4) & Center (2) \\
\hline $\mathrm{N}$ & 2.80 & 1.75 & 7.52 & 6.14 & 7.57 & 0.33 & 0.55 & 0.84 \\
\hline $\mathrm{O}$ & 4.08 & 1.69 & 1.91 & 1.40 & 0.85 & 6.81 & 10.36 & 1.25 \\
\hline $\mathrm{Al}$ & 1.64 & 3.77 & 1.58 & 1.49 & 1.42 & 29.11 & 88.81 & 2.00 \\
\hline $\mathrm{Si}$ & $\mathrm{n} / \mathrm{d}$ & $\mathrm{n} / \mathrm{d}$ & 0.07 & 0.06 & 0.10 & 0.33 & 0.28 & 0.09 \\
\hline $\mathrm{U}$ & 91.29 & 90.37 & 88.29 & 88.99 & 88.00 & 63.42 & $\mathrm{n} / \mathrm{d}$ & 91.54 \\
\hline Mo & 0.18 & 2.42 & 0.63 & 1.92 & 2.06 & $\mathrm{n} / \mathrm{d}$ & $\mathrm{n} / \mathrm{d}$ & 4.28 \\
\hline
\end{tabular}

n/a: not detected.

Table 7. Manufacturing parameters for UMo dispersion type fuel miniplates.

\begin{tabular}{|c|c|c|c|c|c|c|c|c|c|}
\hline \multicolumn{2}{|c|}{ Miniplate Identification } & $\begin{array}{c}\text { UMo-97 } \\
\text { (argon) }\end{array}$ & $\begin{array}{c}\text { UMo-102 } \\
\text { (argon) }\end{array}$ & $\begin{array}{l}\text { UMo-103 } \\
\text { (nitrogen) }\end{array}$ & $\begin{array}{l}\text { UMo-104 } \\
\text { (nitrogen) }\end{array}$ & $\begin{array}{l}\text { UMo-105 } \\
\text { (nitrogen) }\end{array}$ & $\begin{array}{l}\text { UMo-106 } \\
\text { (nitrogen) }\end{array}$ & $\begin{array}{l}\text { UMo-107 } \\
\text { (nitrogen) }\end{array}$ & $\begin{array}{l}\text { UMo-108 } \\
\text { (nitrogen) }\end{array}$ \\
\hline \multicolumn{2}{|c|}{ Uranium Density gU/cm³ } & 6.0 & 8.0 & 6.0 & 6.0 & 7.0 & 7.0 & 8.0 & 8.0 \\
\hline \multicolumn{2}{|c|}{ UMo Fuel Mass [g] } & 5.93 & 6.40 & 5.93 & 5.93 & 6.18 & 6.18 & 6.40 & 6.40 \\
\hline \multicolumn{2}{|c|}{ Mass $(\mathrm{Al}+4 \% \mathrm{Si})[\mathrm{g}]$} & 1.52 & 1.05 & 1.52 & 1.52 & 1.27 & 1.27 & 1.05 & 1.05 \\
\hline \multirow{4}{*}{$\begin{array}{l}\text { Compact } \\
\text { Metrology }\end{array}$} & 22.41 & 22.41 & 22.41 & 22.40 & 22.40 & 22.40 & 22.40 & 22.40 & 22.40 \\
\hline & 18.0 & 18.0 & 18.0 & 18.0 & 18.0 & 18.0 & 18.0 & 18.0 & 18.0 \\
\hline & 2.47 & 2.47 & 2.47 & 2.80 & 2.47 & 2.50 & 2.64 & 2.46 & 2.47 \\
\hline & 86.2 & 86.2 & 86.2 & 86.7 & 86.5 & 83.3 & 83.1 & 81.9 & 82.0 \\
\hline \multirow{2}{*}{$\begin{array}{c}\text { Meat } \\
\text { Metrology }\end{array}$} & 18.8 & 18.8 & 18.8 & 18.0 & 18.0 & 18.0 & 18.0 & 18.0 & 18.8 \\
\hline & Thickn. (mm) & 0.65 & 0.65 & 0.69 & 0.68 & 0.67 & 0.66 & 0.64 & 0.64 \\
\hline \multicolumn{2}{|c|}{ Meat Volume $\left(\mathrm{cm}^{3}\right)$} & 1.04 & 1.05 & 1.08 & 1.06 & 1.00 & 0.99 & 0.94 & 0.99 \\
\hline \multicolumn{2}{|c|}{ Volume fraction matrix } & 0.50 & 0.39 & 0.50 & 0.50 & 0.45 & 0.45 & 0.39 & 0.39 \\
\hline \multirow{3}{*}{$\begin{array}{l}\text { Miniplate } \\
\text { metrology }\end{array}$} & Length (mm) & 130.17 & 130.21 & 130.42 & 130.51 & 130.40 & 130.24 & 130.36 & 130.21 \\
\hline & Wide (mm) & 51.32 & 50.64 & 50.92 & 50.53 & 50.69 & 50.63 & 50.55 & 50.82 \\
\hline & Thickn. (mm) & 1.44 & 1.44 & 1.43 & 1.43 & 1.43 & 1.42 & 1.43 & 1.42 \\
\hline \multicolumn{2}{|c|}{ Starting Thickness (mm) } & 5.80 & 5.48 & 5.80 & 5.76 & 5.63 & 5.58 & 5.42 & 5.40 \\
\hline \multicolumn{2}{|c|}{ Total Reduction (\%) } & 75.1 & 73.8 & 75.3 & 75.2 & 74.7 & 74.5 & 73.7 & 73.7 \\
\hline
\end{tabular}




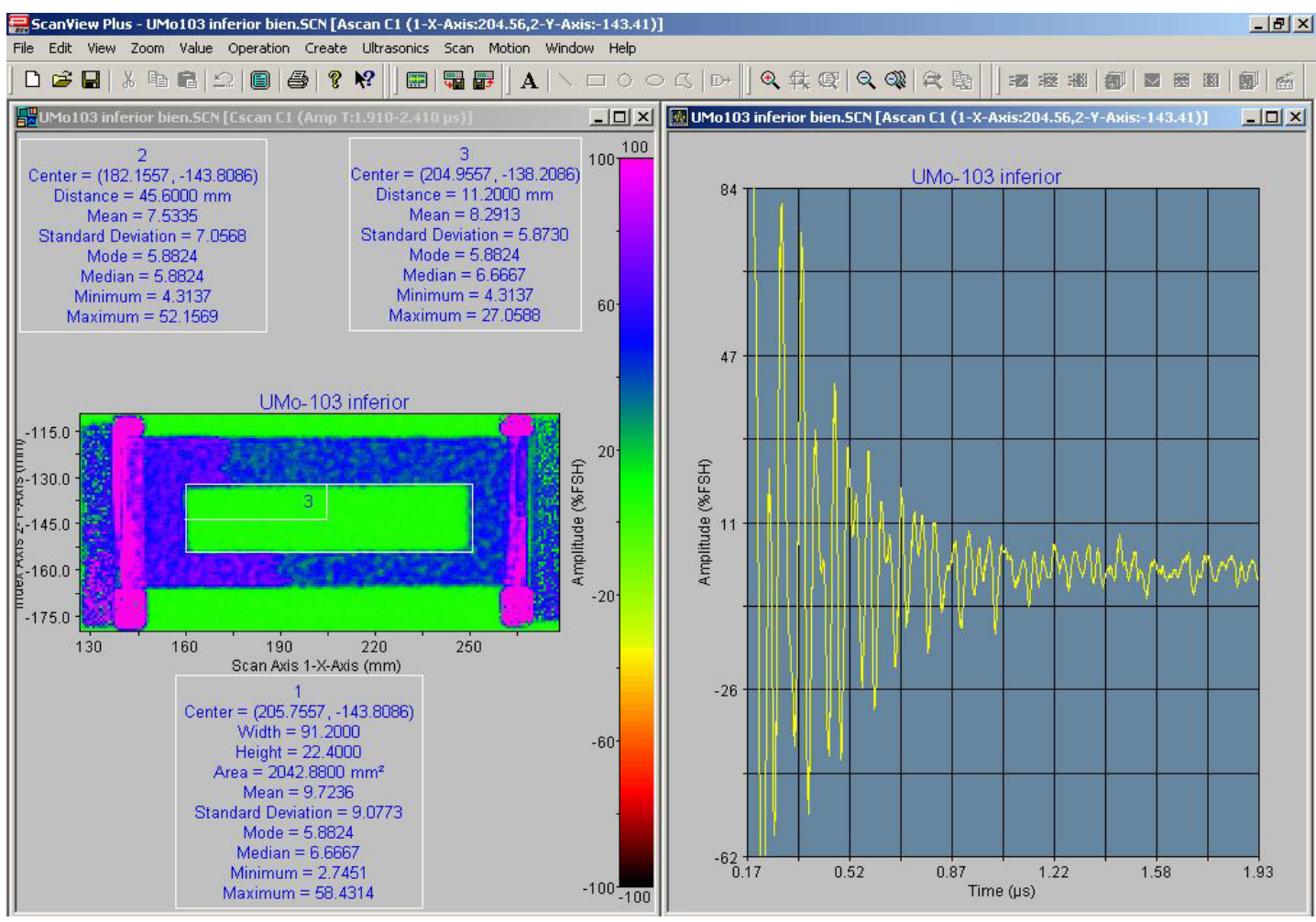

Figure 8. UT inspection of miniplate (UMo-103).
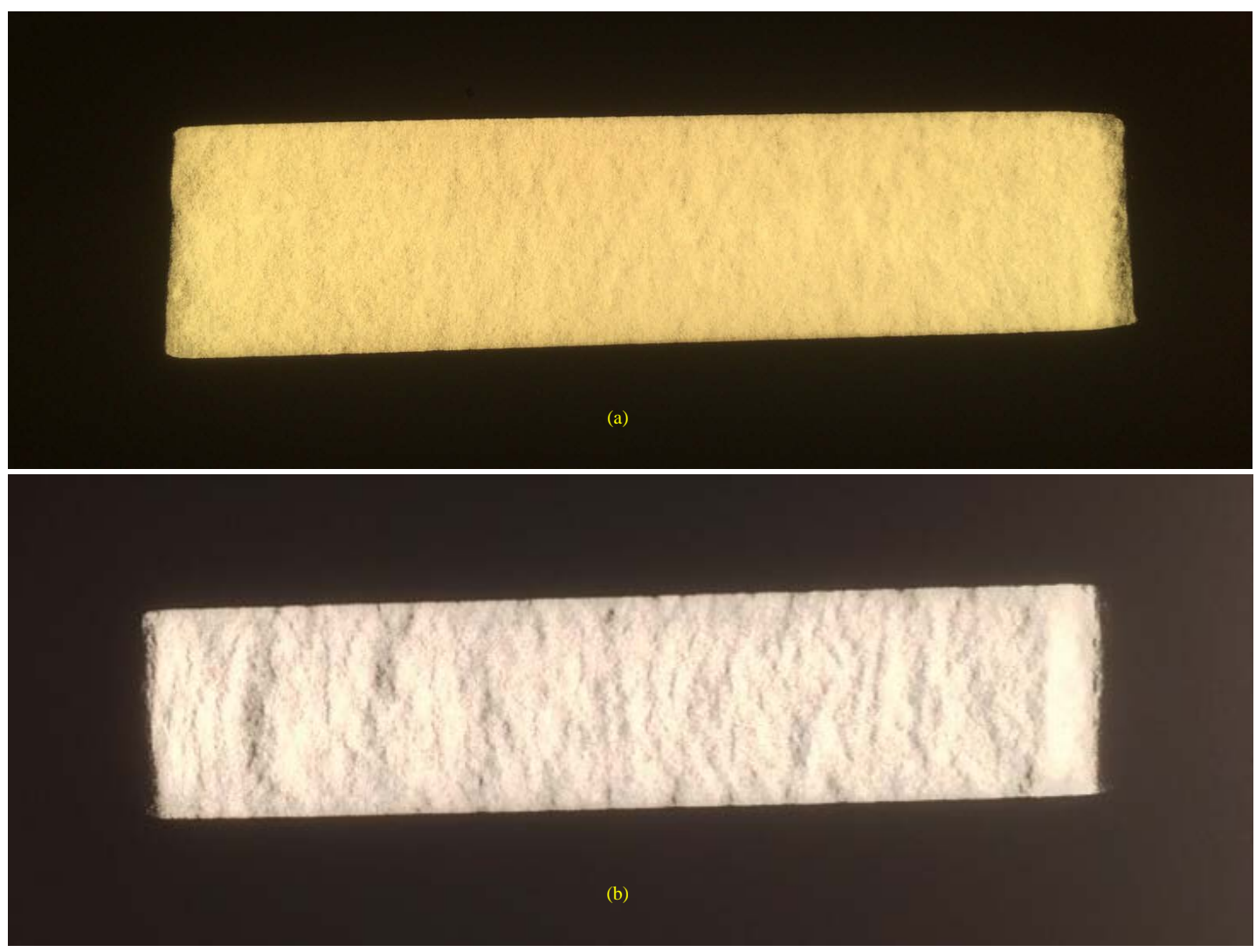

Figure 9. X-Ray images of miniplates (meat zone): (a) UMo-107 (nitrogen), (b) UMo-102 (argon). 
The results of ultrasonic scanning test, carried out in eco-pulse mode, reveal the absence of non-bonding areas. Besides, is possible to observe an UT waveform, characteristic of UMo dispersion fuel. Images of UT inspection, corresponding to UMo-103 miniplate is included in Figure 8.

Results of industrial X-Ray inspection are shown in Figure 9. The radiography (a) corresponds to the miniplate manufactured with particles atomized in nitrogen, where is possible to observe improvement in the homogeneity of particles distribution, compared with the image (b), taken from a miniplate based on particles atomized in argon.

The improvement in the homogeneity can be related with the modification in size distribution of UMo particles. As has been mentioned before, the addition of nitrogen to UMo alloy may produce larger particles and more narrow size distribution. On the other hand, the particles with spherical shape obtained by Rotating Electrode Process are easily segregated, or relocated, during the mixing with aluminium powder and even after, in the matrix, during the rolling process [17].

\section{Conclusions}

The centrifugal atomization of U-7wt\% Mo alloy, conducted under nitrogen atmosphere, was achieved without significant differences in the process, compared with the atomization in argon.

The particle size distribution was the main difference between particles atomized under argon and nitrogen. The presence of nitrogen could increase the melting point and decrease the density of UMo alloy [10]. As a consequence of this, the diameter of particles atomized in nitrogen was increased.

The surface of the UMo particles atomized in argon, analyzed by XRD, reveals the presence of $\mathrm{UO}_{2}$ and $\gamma-\mathrm{U}$. In case of particles atomized under nitrogen, the same compounds were detected, and additionally, peaks of uranium nitride UN.

$\mathrm{UMo} / \mathrm{Al}$ interaction test confirms that the nitrogen addition can decrease but not eliminate this phenomena, nevertheless, the content of $\mathrm{Al}$ into the UMo particles was lower in particles atomized under nitrogen atmosphere.

\section{Acknowledgements}

The authors wish to express their acknowledgments to CCHEN's Nuclear Fuel Section Staff.

\section{References}

[1] Olivares, L., Lisboa, J., Marin, J., Barrera, M., Gutiérrez, C., Chávez, J.C. and Miranda, G. (2014) Characterization of Si-Coated UMo Fuel Particles before and after Interaction Annealing. Proceedings of the 35th International Meeting on Reduced Enrichment for Research and Test Reactors, Vienna, 12-16 October 2014.

[2] Palancher, H., Bonnin, A., Colin, C.V., Nassif, V., Honkimäki, V., Jungwirth, R., Ritter, C., Champion, G. and Calzavara, Y. (2013) UMo/Al Nuclear Fuel Plate Behavior under Thermal Treatment (425-550 ${ }^{\circ}$ C). Powder Di-Fraction, 28.

[3] Jeong, Y.J., Park, J.M., Ryu, H.J., Lee, Y.S., Kim, W.J., Junwirth, R., Chiang, H.-Y., Zweifel, T. and Petry, W. (2013) Proceedings of the European Research Reactor Conference, St. Petersburg, 21-25 April 2013.

[4] Kim, Y.S., Park, J.M., Lee, K.H. and Yoo, B.O. (2014) Post Irradiation Analysis of U-Silicide or U-Nitride Coated U-7Mo/Al Dispersion Fuel. Proceedings of the European Research Reactor Conference, Ljubljana, 23-27 April 2014.

[5] Breitkreutz, H., Jungwirth, R., Rohrmoser, A., Petry, W., Van Den Berghe, S., Leenaers, A., Koonen, E., Lemoine, P., Ripert, M., Palancher, H., Anselmet, M.C., Jarousse, C., Stepnik, B., Geslin, D., Calzavara, Y. and Guyon, H. (2013) The Development of Disrse UMo as a High Performance Research Reactor Fuel in Europe. Proceedings of the European Research Reactor Conference, St. Petersburg, 21-25 April 2013.

[6] Bugl, J. and Bauer, A.A. (1964) Phase Relations in the System Uranium-Nitrogen. Journal of the American Ceramic Society, 47, 425-429. http://dx.doi.org/10.1111/j.1151-2916.1964.tb14429.x

[7] Okamoto, H. (1997) NU (Nitrogen-Uranium). Journal of Phase Equilibria, 18, 107. http://dx.doi.org/10.1007/BF02646768

[8] Noboru, Hirayama, S., Tanabe, I., Muramatsu, A. and Kawada, T. (1972) Preparation of High Density Uranium Nitride and Uranium Carbonitride Fuel Pellets. Journal of Nuclear Science and Technology, 521-527.

[9] Olivares, L., Marin, J., Barrera, M., Gutierrez, C. and Lisboa, J. (2012) Dispersion Fuel Miniplates Based on UMo Powder Produced by Centrifugal Atomization. Proceedings of the 34th International Meeting on Reduced Enrichment for Research and Test Reactors, Warsaw, 14-17 October 2012. 
[10] Clark, C.R., Muntifering, B.R. and Jue, J.F. (2007) Production and Characterization of Atomized U-Mo Powder by the Rotating Electrode Process. Proceedings of the 28th International Meeting on Reduced Enrichment for Research and Test Reactor, Czech Republic, 29 October-23-27 November 2007.

[11] Olivares, L., et al. (2011) Status and Progress of R\&D in High Density Nuclear Fuel at the CCHEN. Proceedings of the 33th International Meeting on Reduced Enrichment for Research and Test Reactors, Santiago de Chile, 23-27 October 2011.

[12] Schenk, R., et al. (2013) FRM II/CERCA UMo Atomizer Project Status. Proceedings of the European Research Reactor Conference, St. Petersburg, 21-25 April 2013.

[13] Dunkley, J.J. (2006) Atomization for Metals-Craft or Science. Proceedings of 2nd International Conference on Spray Deposition and Melt Atomization, Bremen Universitat, 1-6.

[14] Kim, K.H., Lee, D.B., Kim, C.K., Hofman, G.E. and Paik, K.W. (1997) Characterization of U2wt\%Mo and U.1wt\%Mo Alloy Powders Prepared by Centrifugal Atomization. Journal of Nuclear Materials, 245, 179-184. http://dx.doi.org/10.1016/S0022-3115(97)00011-1

[15] Dubois, S., et al. (2006) Development of UMo/Al Dispersion Fuel: An Oxide Layer as a Protective Barrier around the UMo Particles. Proceedings of the 27th International Meeting on Reduced Enrichment for Research and Test Reactor, Cape Town, 29 October-2 November 2006.

[16] Ryu, H.J., Park, J.S., Park, J.M. and Kim, C.K. (2011) The Effect of Si-Rich Layer Coating on U-Mo vs. Al Interdiffusion. Nuclear Engineering and Technology, 43, 159-166. http://dx.doi.org/10.5516/NET.2011.43.2.159

[17] Clark, C.R. and Meyer, M.K. (1998) Fuel Powder Production from Ductile Uranium Alloys. Proceedings of the 21th International Meeting on Reduced Enrichment for Research and Test Reactors, Sao Paulo, 18-23 October 1998. 